\title{
Assessment of the Maya's Beliefs and Preferences on Bonesetters and Bone Fracture Treatment in the Guatemalan Highlands: A Household Survey
}

\author{
Bennett W. Hartley ${ }^{1} \&$ Craig A. Sinkinson ${ }^{2}$ \\ ${ }^{1}$ Michigan State University College of Human Medicine, Grand Rapids, MI, USA \\ ${ }^{2}$ Mayan Medical Aid Inc., Santa Cruz La Laguna, Guatemala \\ Correspondence: Bennett W. Hartley, Secchia Center, 15 Michigan St. NE, Grand Rapids, MI 49503, USA. Tel: \\ $1-(248)-787-8979$.
}

Received: December 26, 2020 Accepted: January 19, 2021 Online Published: February 10, 2021

doi:10.5539/gjhs.v13n3p89 URL: https://doi.org/10.5539/gjhs.v13n3p89

\begin{abstract}
Background: In the Lake Atitlán region of Guatemala, traditional bonesetters (hueseros) commonly treat bone fractures. The indigenous Kaqchikel population has access to biomedical care, but traditional medicine remains the preferred treatment modality for bone fracture.
\end{abstract}

Methods: Households in four villages were surveyed to assess experiences with bone fracture treatment. Of 108 households sampled, 83 met inclusion criteria and completed the survey. Responses were analyzed to assess for group demographics, bone fracture prevalence, and treatment history. Independence testing assessed for subgroup differences.

Results: Mean age: 40 years old. For fracture treatment, 37\% (31/83) consulted with a physician/nurse whereas $75 \%(62 / 83)$ consulted with a bonesetter. $19 \%(16 / 83)$ consulted with both. Cast immobilization was utilized by only $16 \%(13 / 83)$ of participants. The services provided by bonesetters included massage, temazcal (sweat lodge), herbal poultice, prayer, and recommended rest. When comparing participants that used a cast $(n=13)$ and those that used a bonesetter exclusively $(n=46)$, the bonesetter group had lower rates of continued pain and movement limitation, higher satisfaction with treatment, and higher interest in seeking the same treatment in the future, though these findings were not statistically significant. Regarding future care, 66\% (55/83) would consider consulting a doctor whereas $83 \%(69 / 83)$ would seek services from a bonesetter. 53\% (44/83) would utilize both. If recommended, 46\% (38/83) would consider using a cast. Only 22\% (18/83) of participants reported previous musculoskeletal imaging.

Conclusion: These results suggest a high preference of bonesetters for bone injury treatment, reduced acceptance of biomedical care, and limited acceptance of cast immobilization.

Keywords: bone, bonesetting, bonesetter, fracture, Guatemala, huesero, indigenous, Kaqchikel

\section{Introduction}

There were nearly 140 million new bone fractures worldwide in 2017 according to the most recent Global Burden of Disease study (James et al., 2018). Fractures are commonly due to falls and falls are the $18^{\text {th }}$ leading cause of disability-adjusted life years (Kyu et al., 2018). Following road injuries, falls are the second leading cause of death among non-intentional injury (Roth et al., 2018). Injuries, like falls, leading to bone fractures can be particularly devastating to residents of lower-income countries, like Guatemala.

Guatemala is home to 17.9 million people with a median age of 19.4 years. For comparison, the United States is home to over 322 million people with a median age of 37.4 years (GHO, n.d.; WHO, n.d.; United Nations, n.d.). In Guatemala, $13.7 \%$ of the population are living on less than $\$ 1$ per day $(G H O$, n.d.). According to the most recent 2018 Guatemalan census, there are 22 different Mayan languages across the country with 42-66\% of the population identifying as indigenous Mayan (Montenegro \& Stephens, 2006; Portal de Resultados Del Censo, 2018). Indigenous populations in Latin America usually have higher rates of mortality and morbidity than their nonindigenous counterparts across most health indicators (Montenegro \& Stephens, 2006).

One of the most common Mayan groups in Guatemala are the indigenous Kaqchikel people (Portal de Resultados 
Del Censo, 2018). In the Western Highlands of Guatemala, municipalities on the northern border of Lake Atitlán are largely comprised of indigenous Kaqchikel people. One of these municipalities, Santa Cruz La Laguna, is 99\% indigenous Kaqchikel (Facultad de Ciencias Económicas Universidad de San Carlos de Guatemala, n.d.). This area of Guatemala is nestled in a mountainside along the lake, where most residents travel by foot. Many take public boats to neighboring towns for goods, school, and work. Most of the villages have access to a local health center that is usually staffed by nurses with unpredictable levels of training. Santa Cruz La Laguna has a health center staffed by an American-trained physician who offers free or low-cost medical treatment.

Although much of the community visits this physician for care, many residents are hesitant to receive care for bone fractures, instead opting to visit local traditional bonesetters called hueseros. Relying on their hands for diagnosis and treatment, bonesetters manage musculoskeletal injuries like deep tissue injuries, sprains, and fractures (Hinojosa, 2004). There are many regional differences to bonesetting technique and ability, but, in general, bonesetters utilize their own bodies, oils, and herbs to detect, diagnose, and treat injury. Bonesetters have been in use in numerous countries, including Turkey, China, Mexico, England, and Nigeria (Dada et al., 2011; England, 1844; Hatipoğlu \& Tatar, 1995; Huber \& Anderson, 1996; Smith, 1974). In Guatemala, bonesetters do not require any standardized training or certifications and are trained by fellow bonesetters in the community. In contrast, physicians and nurses require medical degrees and certifications that permit them to practice and care for patients.

There is limited research on the effectiveness of bonesetters as well as the community-held beliefs surrounding their utility around the world, especially in the Guatemalan Highlands. This study was conducted to better understand outcomes and preferences in the community regarding bonesetters.

\section{Methods}

\subsection{Study Area}

Data was collected from in-person household surveys conducted within four villages across two municipalities in the department of Sololá, Guatemala. The municipality of Santa Cruz La Laguna has an estimated population of 7,812 people and three of the surveyed villages (Santa Cruz La Laguna, Tzununa, Jaibalito) reside within this municipality, comprising nearly $75 \%$ of its total population (Estadística, n.d.). (Figure 1) The other municipality (San Marcos La Laguna) is adjacent to these villages and has an estimated population of 2,809 (Estadística, n.d.). These villages are four of the 11 that border Lake Atitlán and nearly $100 \%$ of residents belong to the indigenous Kaqchikel group. Although village-specific demographic data is unavailable, data is available for the department of Sololá, which encompasses the four villages that were surveyed. Sololá comprises $2.9 \%$ of the population of Guatemala and $93.9 \%$ of residents report some level of food insecurity. The material that the houses are constructed with are inadequate for $42 \%$ of residents and there is an inadequate water supply for $10.6 \%$ of residents (Instituto Nacional de Estadística Guatemala., 2014).

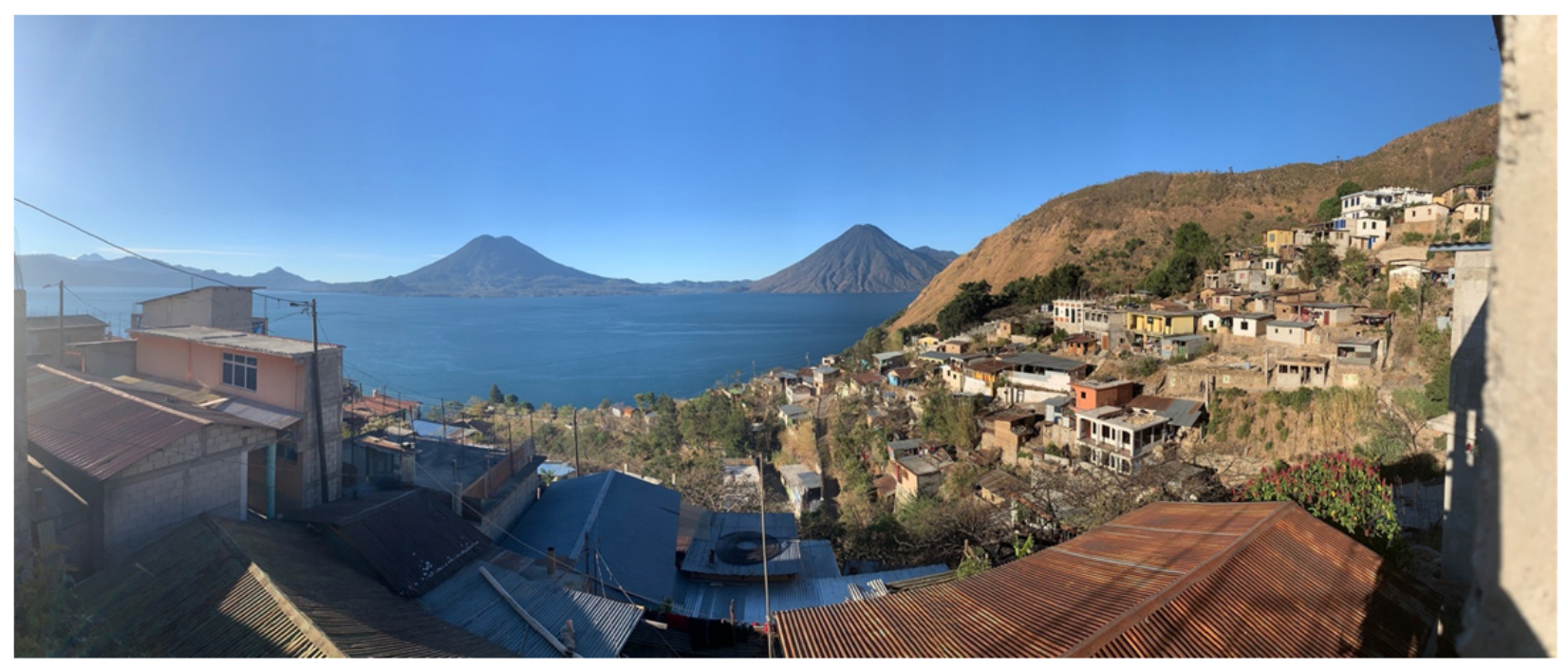

Figure 1. A photograph taken by the investigator of Santa Cruz La Laguna with Lake Atitlán in the distance 


\subsection{Survey}

The survey was developed with the assistance of an American-trained medical doctor in Santa Cruz La Laguna and the staff in his medical clinic. The survey was comprised of 32 questions and each interview took between eight and 15 minutes. Each question was originally developed in English and was then translated to Spanish with the assistance of interpreters in the United States of America and in Guatemala. The questions were reviewed by a local Guatemalan physician, nurses, and community members to ensure they were culturally appropriate. The finalized survey was approved by the Michigan State University Institutional Review Board. A local interpreter would verbally translate the questions to Kaqchikel when interviewing participants for the study.

\subsection{Ethics}

The experimental protocols were approved by the Michigan State University Institutional Review Board. While there was no local Institutional Review Board in Guatemala that could have provided formal approval, the project was conducted with the approval of local community leaders and organizations, including the local health department. All participants provided oral consent to be included in the study. Written consent was not obtained for two reasons. First, the Kaqchikel language that is spoken in these communities is not a written language, so producing a written consent form would not be possible. Second, a signature is not a socially acceptable or understood concept in the communities surveyed. The participants would likely not understand the significance of a signature. The Institutional Review Board understood this and accepted oral-only consent for this study. Prior to each interview, the interpreter provided an oral description of the study to the participant and asked if the participant would consent to participate. No names, addresses, contact information, or other personal identifiable information were requested or documented, making each recorded interview response anonymous. For these reasons, there were minimal risks to participants.

\subsection{Procedure, Inclusion Criteria, and Participant Recruitment}

The investigator and a local interpreter interviewed residents of the communities over a two-week span. Participants were selected randomly from households in the communities of interest. Households were selected randomly throughout the entire respective village to attract a variety of participants with myriad experiences. A random number generator was used to identify homes in each village to be surveyed. Individuals must have been $\geq$ 18 years of age and had a personal or family history of bone fractures to be eligible for the study. Any resident that was a family member of another participant was not eligible for the study in order to further encourage differing beliefs and experiences.

The interviews were conducted in Kaqchikel, the native language to the communities. Responses were verbally translated to Spanish by the interpreter and the investigator recorded the answers. Each interview was conducted on weekdays between 8:30am-12:30pm local time.

An additional interview was conducted with a local Huesero in San Marcos La Laguna. She provided information on common practices and beliefs of hueseros. Her responses are summarized in the results section.

\subsection{Data and Statistics}

Responses from each participant were manually entered into a Microsoft Excel spreadsheet. Statistical analysis of this dataset was performed using Microsoft Excel. Quantitative data between subgroups was compared using a Fisher exact test of independence. Significance was assessed at $\mathrm{p}<0.05$.

\section{Results}

\subsection{Demographics}

With the assistance of the interpreter, 108 residents were asked if they themselves or any member of their family had experienced a bone fracture in the past. Of the 108 residents, 83 individuals answered in the affirmative and subsequently completed the 32-question survey.

Of the 83 participants, the average age was 39.98 years (range 18-83) and 58 (70\%) were female. There were 62 (75\%) married participants and 78 (94\%) participants attend church at least once per week. 42 (51\%) participants have a pastor or religious figure within their family. (Table 1) 
Table 1. Participant characteristics

\begin{tabular}{llc}
\hline Variable & & Frequency (\%) or Mean (range) \\
\hline \multirow{2}{*}{ Sex } & Female & $58(70 \%)$ \\
& Male & $25(30 \%)$ \\
\hline \multirow{4}{*}{ Age } & Average age & $39.98(18-83)$ \\
& $18-30$ years & $26(31 \%)$ \\
& $31-50$ years & $42(51 \%)$ \\
& $51-70$ years & $11(13 \%)$ \\
Marital status & $\geq 71$ years & $4(5 \%)$ \\
& Married & $62(75 \%)$ \\
& Single \& no prior marriage & $15(18 \%)$ \\
& Divorced & $1(1 \%)$ \\
& Widow & $2(2 \%)$ \\
& In a relationship & $3(4 \%)$ \\
\hline \multirow{3}{*}{ eeligion \& Family } & Attends church weekly & $78(94 \%)$ \\
& Family member is a pastor/religious figure & $42(51 \%)$ \\
& Family member is a bonesetter & $5(6 \%)$ \\
& Family member is a nurse & $3(4 \%)$ \\
& Family member is a doctor & $0(0 \%)$ \\
\hline
\end{tabular}

\subsection{Medical Behavior}

There were 57 (68\%) participants who had consulted with a medical doctor in the last 30 days (range 1-1,095 days). Additionally, $32(39 \%)$ participants visit a medical doctor for their regular healthcare whereas 61 (73\%) participants visit their local community health center, which are staffed by nurses. Some participants visit both depending on the health concern. (Table 2)

Table 2. Medical behavior

\begin{tabular}{ll}
\hline Variable & Frequency (\%) \\
\hline Consulted with a doctor or nurse in last 30 days & $57(69 \%)$ \\
Visit a medical doctor for primary care & $32(39 \%)^{*}$ \\
Visit a nurse at a local health center for primary care & $61(73 \%)^{*}$ \\
Visit a spiritual healer for primary care & $0(0 \%)$ \\
\hline
\end{tabular}

* Due to some participants visiting both nurses and doctors interchangeably for primary care, the values exceed $100 \%$.

\subsection{Bone Fracture History}

Of the 83 participants who have been affected by bone fractures, 35 (42\%) participants have fractured a bone themselves and 60 (77\%) participants have had a family member fracture a bone. Some participants have fractured a bone and, additionally, had a family member fracture a bone. Of these fractures, 49 (59\%) participants (or their families) have experienced a fracture in the last 5 years. The most common areas of the body that were fractured were ankle (19\%), wrist (18\%), knee (17\%), elbow (14\%), arm (12\%), shoulder (10\%), and leg $(6 \%)$. The most common cause of bone fractures were falls $(90 \%)$. (Table 3 ) 
Table 3. Bone fracture history

\begin{tabular}{|c|c|c|}
\hline Variable & & Frequency $(\%)$ \\
\hline \multirow{2}{*}{ Individual who fractured bone* } & Participant & $35(42 \%)$ \\
\hline & Participant's family member & $60(77 \%)$ \\
\hline \multirow{9}{*}{ If family member, the relation to the participant $* *$} & Son & $17(33 \%)$ \\
\hline & Brother & $10(19 \%)$ \\
\hline & Husband & $7(13 \%)$ \\
\hline & Daughter & $4(8 \%)$ \\
\hline & Father & $4(8 \%)$ \\
\hline & Sister & $4(8 \%)$ \\
\hline & Mother & $3(6 \%)$ \\
\hline & Wife & $2(4 \%)$ \\
\hline & Nephew & $1(2 \%)$ \\
\hline \multirow{3}{*}{ Recency of fracture } & Past 5 years & $49(59 \%)$ \\
\hline & Past 10 years & $65(78 \%)$ \\
\hline & Past 16 years & $75(90 \%)$ \\
\hline \multirow{8}{*}{ Area of the body ${ }^{+}$} & Ankle & $16(19 \%)$ \\
\hline & Wrist & $15(18 \%)$ \\
\hline & Knee & $14(17 \%)$ \\
\hline & Elbow & $12(14 \%)$ \\
\hline & Arm & $10(12 \%)$ \\
\hline & Shoulder & $8(10 \%)$ \\
\hline & Leg & $5(6 \%)$ \\
\hline & Other & $5(6 \%)$ \\
\hline \multirow{4}{*}{ Cause of fracture } & Fall & $75(90 \%)$ \\
\hline & Vehicle accident & $6(7 \%)$ \\
\hline & Boat accident & $1(1 \%)$ \\
\hline & Other & $1(1 \%)$ \\
\hline
\end{tabular}

* Due to some participants fracturing a bone and, additionally, having a family member fracture a bone, the values exceed $100 \%$

** Some participants failed to report the specific relation of the family member, so the values do not sum to 60

${ }^{\dagger}$ Due to some participants fracturing in multiple locations, the values exceed $100 \%$.

\subsection{Bone Fracture Treatment}

Of the 83 participants who have been affected by bone fractures, 31 (37\%) participants consulted with a doctor or nurse and $62(75 \%)$ participants consulted with a bonesetter. Some participants consulted with both a doctor or nurse and a bonesetter.

Of the 31 participants who consulted with a doctor or nurse for diagnosis or treatment of their bone fracture, 13 $(42 \%)$ visited the hospital in Sololá, $8(26 \%)$ visited the nurses at the community health center, $7(23 \%)$ visited the medical doctor in Santa Cruz La Laguna, and 6 (19\%) visited a different medical doctor. Of these participants, 24 (77\%) received pain medication, $15(48 \%)$ received recommendations to wear a cast, and $2(6 \%)$ underwent surgery.

Of the 62 participants who visited a bonesetter for treatment, $59(95 \%)$ received a massage, $43(69 \%)$ used a temazcal, $50(81 \%)$ used herbal poultice, $28(45 \%)$ used prayer, and $7(11 \%)$ had their medication blessed by the 
bonesetter. A temazcal is a stone/cement sweat lodge that many families build next to their homes. (Figure 2) Residents frequently use them for bathing and medicinal purposes. A poultice is a soft mass that is often infused with herbs, oils, or medicine. The poultice is then rubbed and massaged onto the injured area. Sometimes this poultice is made of animal or human bone. Additionally, $93 \%$ of those who visited with a bonesetter rested for a duration of time afterwards to allow their fracture to heal. Of those participants who rested, the median amount of rest was 60 days (range 7-730).

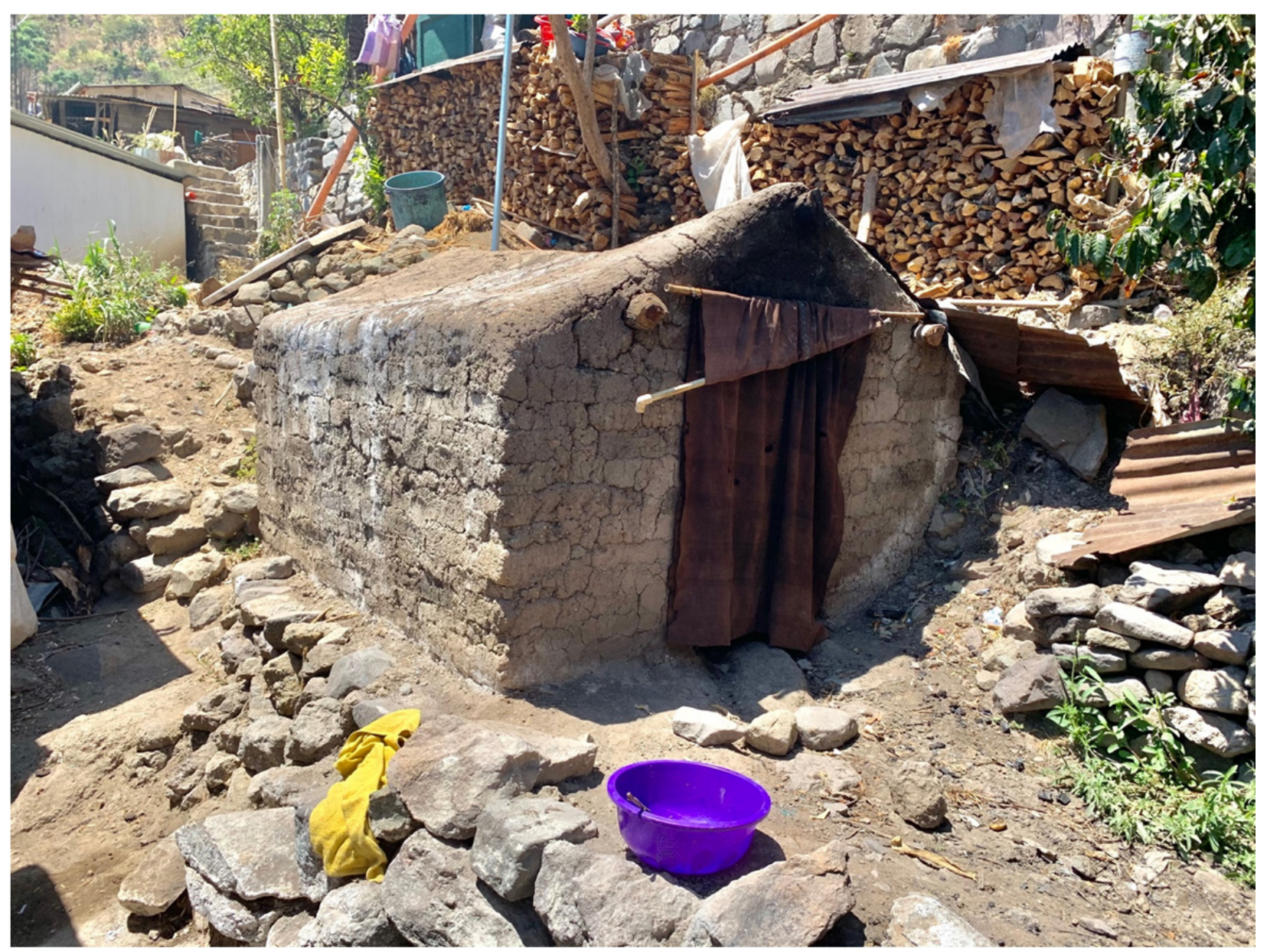

Figure 2. A photograph taken by the investigator of a temazcal in San Marcos La Laguna

There were an additional $8(10 \%)$ participants who treated themselves without visiting a doctor, nurse, or bonesetter. Moreover, 38 (46\%) participants visited a church for prayer after fracturing a bone.

Of the 15 participants who had their fractured bone placed in a cast, 2 (13\%) participants took their cast off early due to pain. Of the 15 participants, $11(73 \%)$ received their cast from the hospital in Sololá. Of the 13 participants that wore their cast for the full recommended time, the median length of time was 8 weeks (range 4-104). (Table 4) 
Table 4. Bone fracture treatment

\begin{tabular}{|c|c|c|}
\hline Variable & & $\begin{array}{c}\text { Frequency (\%) or Amount of } \\
\text { days/weeks }\end{array}$ \\
\hline \multirow{4}{*}{ After injury, participant consulted with } & Doctor/nurse & $31(37 \%)$ \\
\hline & Bonesetter & $62(75 \%)$ \\
\hline & Doctor/nurse \& bonesetter & $16(19 \%)$ \\
\hline & $\begin{array}{l}\text { Did not seek any medical attention } \\
\text { (treated self) }\end{array}$ & $8(10 \%)$ \\
\hline \multirow{3}{*}{$\begin{array}{l}\text { Specific provider that participants consulted with } \\
\text { who visited a doctor/nurse }\end{array}$} & Hospital in Sololá & $13(42 \%)$ \\
\hline & Nurse at local health center & $8(26 \%)$ \\
\hline & Physician not at Sololá hospital & $13(42 \%)$ \\
\hline \multirow{5}{*}{ Treatment received from doctor/nurse } & Pain medication & $24(77 \%)$ \\
\hline & Cast immobilization & $15(48 \%)$ \\
\hline & Temazcal & $1(3 \%)$ \\
\hline & Herbal poultice & $1(3 \%)$ \\
\hline & Surgery & $2(6 \%)$ \\
\hline \multirow{7}{*}{ Treatment received from bonesetter } & Massage & $59(95 \%)$ \\
\hline & Recommended rest & $54(93 \%)^{\dagger}$ \\
\hline & Herbal poultice & $50(81 \%)$ \\
\hline & Temazcal & $43(69 \%)$ \\
\hline & Prayer & $28(45 \%)$ \\
\hline & Blessing the medication & $7(11 \%)$ \\
\hline & Splint/Bandaging & $1(2 \%)$ \\
\hline \multirow{2}{*}{ Recommended rest from bonesetter } & Median number of days & 60 days \\
\hline & Range of days & $7-730$ days \\
\hline \multirow{2}{*}{ Treatment from church } & Visited church for prayer & $38(46 \%)$ \\
\hline & Church blessed medication & $4(5 \%)$ \\
\hline \multirow{4}{*}{ Cast immobilization } & A cast was recommended & $15(18 \%)$ \\
\hline & $\begin{array}{l}\text { Used a cast for full recommended } \\
\text { duration }\end{array}$ & $13(16 \%)$ \\
\hline & Median time spent with cast & 8 weeks \\
\hline & Range of time spent with cast & $4-104$ weeks \\
\hline Radiography & Received an X-ray of injured area & $18(22 \%)$ \\
\hline
\end{tabular}

* Due to some participants consulting with both a doctor/nurse and bonesetter, the values exceed 100\%.

${ }^{\dagger}$ Did not begin asking about rest until participant $\# 11$.

\subsection{Bone Fracture Outcomes}

Of the 83 participants who have been affected by bone fractures, $50(60 \%)$ still have pain, $30(36 \%)$ have limited movement, $56(67 \%)$ are satisfied with the treatment, and $70(84 \%)$ would pursue the same treatment plan in the future. When comparing the group of participants that used a cast $(n=13)$ with the group that only used a bonesetter $(n=46)$, the bonesetter group had a lower proportion of individuals with pain and limited movement and an higher proportion that were satisfied and would pursue the same treatment in the future. However, none of these findings were statistically significant with a significance level of $p<0.05$ using a Fisher exact test of independence. These groups were selected for comparison because the appropriate biomedical treatment for most 
fractures involves cast immobilization. By comparing these two groups, the effectiveness of biomedical treatment can be compared to that of traditional medicine. Of the 83 participants affected by bone fractures, only 18 (22\%) have previously received any type of musculoskeletal imaging (X-Ray, CT, MRI).

Of the 13 participants who would seek different fracture treatment in the future, $5(38 \%)$ would visit a medical doctor, 5 (38\%) would visit a bonesetter, and 3 (23\%) would not seek any medical care. (Table 5)

Table 5. Bone fracture outcomes

\begin{tabular}{|c|c|c|c|c|}
\hline Variable & $\begin{array}{c}\text { All } \\
\text { participants }\end{array}$ & $\begin{array}{l}\text { Used a cast for } \\
\text { full duration }\end{array}$ & $\begin{array}{l}\text { Only consulted } \\
\text { with bonesetter }\end{array}$ & $\begin{array}{l}\text { Significance (p-value } \\
\text { using Fisher exact test) }\end{array}$ \\
\hline \# of participants & 83 & 13 & 46 & \\
\hline Bone has recovered fully & $74(89 \%)$ & $11(85 \%)$ & $43(93 \%)$ & 0.3025 \\
\hline Current pain & $50(60 \%)$ & $9(69 \%)$ & $26(57 \%)$ & 0.5292 \\
\hline Current movement limitations & $30(36 \%)$ & $6(46 \%)$ & $15(33 \%)$ & 0.5131 \\
\hline Satisfied with treatment & $56(67 \%)$ & $8(62 \%)$ & $34(74 \%)$ & 0.4906 \\
\hline $\begin{array}{l}\text { Would receive same treatment if } \\
\text { experienced a future fracture }\end{array}$ & $70(84 \%)$ & $10(77 \%)$ & $43(93 \%)$ & 0.1141 \\
\hline
\end{tabular}

Note. Significance was evaluated by testing the subgroup that used a cast against the subgroup that only consulted with a bonesetter to assess for independence.

\subsection{Future Treatment Preferences}

In the future, if the participants were to suspect they fractured a bone, 70 (84\%) would seek treatment the same day. Of the 83 participants, if a bone fracture was suspected, 55 (66\%) participants would consider visiting a doctor, 69 $(83 \%)$ would consider visiting a bonesetter, and $71(87 \%)$ would consider visiting a pastor for prayer.

Of the 55 participants that would visit a doctor, $43(78 \%)$ would only do so if they believed the fracture to be severe. Only $11(20 \%)$ would visit a doctor for all suspected fractures. Of the $69(83 \%)$ participants that would visit a bonesetter, 37 (57\%) would do so only for minor fractures and 29 (42\%) would do so for all suspected fractures.

If a participant was seeking to diagnose a suspected bone fracture, $45(54 \%)$ would consult with a medical doctor, $50(60 \%)$ would consider imaging, and $62(75 \%)$ would consult with a bonesetter. If a participant was seeking treatment after a confirmed bone fracture diagnosis, $67(81 \%)$ would accept pain medication from a medical doctor, $38(46 \%)$ would accept a cast if necessary, 68 (82\%) would seek recommendations from a bonesetter, and 44 (53\%) would accept surgical intervention if necessary. Overall, 75 (90\%) participants believe that a bonesetter can provide some benefit if they were to fracture a bone. (Table 6)

Table 6. Future treatment preferences

\begin{tabular}{lll}
\hline Variable & & Frequency (\%) \\
\hline & Doctor & $55(66 \%)$ \\
If suspecting a fracture, would consider visiting $a$ & Bonesetter & $69(83 \%)$ \\
& Religious figure & $71(87 \%)$ \\
Would consult a doctor & If severe & $43(52 \%)$ \\
& If minor & $1(1 \%)$ \\
Would consult a bonesetter & For all suspected fractures & $11(13 \%)$ \\
\hline & If severe & $3(4 \%)$ \\
If seeking a fracture diagnosis, participant would consider & If minor & $37(45 \%)$ \\
& For all suspected fractures & $29(35 \%)$ \\
\hline
\end{tabular}




\begin{tabular}{lll}
\hline & Medication from doctor & $67(81 \%)$ \\
& Cast immobilization if necessary & $38(46 \%)$ \\
If seeking fracture treatment, participant would consider & Rest & $67(81 \%)$ \\
& Recommendations of bonesetter & $68(82 \%)$ \\
& Prayer from a religious figure & $72(86 \%)$ \\
& Surgery if necessary & $44(53 \%)$ \\
\hline If uninterested in ever receiving a cast, it is due to & Pain & $11(13 \%)$ \\
& Movement limitation & $8(10 \%)$ \\
Bonesetter & Skin irritation & $3(4 \%)$ \\
\hline
\end{tabular}

* Did not begin asking about rest until participant \#11.

\subsection{Huesero Interview}

In addition to interviewing the study participants, we interviewed a bonesetter in San Marcos La Laguna regarding her bonesetting practice. She noted that most bonesetters in the community do not practice bonesetting full-time, but rather provide bone treatment as needed, which for her occurred about once per month. They practice free of charge, but usually ask for a small donation if the patient can provide one. They practice bonesetting due to a spiritual belief that they have special powers to do so. The bonesetter we spoke with had a dream seven years prior telling her she could heal bones. Because of that experience, she feels obligated to treat patients and views it as a calling. She noted that most of the villages along Lake Atitlán have their own bonesetters, so patients normally do not need to leave the village they reside in for treatment. Her treatment for bone fractures normally involves massage of the injured area and superficial application of an oil blend she creates that includes marijuana. She also advises her patients to rest for a period of time and to return multiple times for further massage and oil application. She also recommends the use of a temazcal. She has not undergone any formal healthcare education. She noted that many residents utilize bonesetters instead of biomedical care due to the ease of access and the reduced cost of care.

\section{Discussion}

This study appears to be the first study that examines patient-reported outcomes of bonesetters in Guatemala. We were able to find one article that explores the impact of radiography on the practice of bonesetters in Guatemala, but it did not seek to assess outcomes (Hinojosa, 2004). Additionally, no studies have been published on bone fracture treatment outcomes by bonesetters in the four countries that border Guatemala (Belize, El Salvador, Honduras, and Mexico). However, there is some literature on the general use and social structure of bonesetters in Mexico (Anderson, 1987; Arcury et al., 2016; Hoff, 1997; Huber \& Anderson, 1996). One 1997 study demonstrated potential benefits of providing basic healthcare training to traditional health providers in Mexico, Ghana, and Bangladesh (Hoff, 1997). A 1987 study followed a traditional bonesetter in Mexico who managed patients with musculoskeletal conditions and demonstrated some potential benefit, but this provider was not treating bone fractures (Anderson, 1987). A more recent 2016 study found that of 100 Mexican immigrants working a seasonal farming job in North Carolina, $43 \%$ had previously used a bonesetter, demonstrating the high prevalence of bonesetter use (Arcury et al., 2016).

Although the literature on traditional bonesetters in and around Guatemala is limited, there are several studies on bonesetting outcomes in Africa, Asia, and Finland. Two studies out of Finland found that bonesetting for nonspecific back pain (not bone fractures) was more effective than exercise or physiotherapy for pain relief and physical function (Hemmilä et al., 1997, 2002). A 2018 study from China found that bonesetting manipulation in addition to surgery for treatment of hallux valgus (bunions) provided beneficial results (Chen et al., 2018). Additionally, two studies from Nigeria and Ghana supported the use of bonesetters working in parallel with hospital providers (Ariës et al., 2007; Dada et al., 2011). However, it is important to note that none of these studies supported patients solely relying on bonesetters for care, especially regarding fractures.

When using bonesetters as your sole provider for musculoskeletal injury, serious complications can arise. Studies from Turkey and Nigeria have detailed the consequences patients face when delaying hospital care in favor of 
bonesetter treatment (Dada et al., 2011; Odatuwa-Omagbemi et al., 2018; Zehir, 2015). A serious consequence can be gangrene, colloquially called "bone setters' gangrene," that studies from western Africa have detailed (Bickler \& Sanno-Duanda, 2000; Onuminya et al., 1999).

One of the major findings from our study is that more participants consulted with a bonesetter $(75 \%)$ than with a doctor or nurse (37\%) for bone fracture treatment. This finding demonstrates the overwhelming preference for bonesetters within these four villages and the significant portion of individuals who never consulted with a biomedical provider (doctor/nurse). It is suspected that patients prefer bonesetters due to the ease of access, the familiarity with the bonesetters (since most are members of the patient's community), and the low cost. Another significant finding is that only $16 \%$ of participants utilized cast immobilization. This result demonstrates the community's aversion to casts and the disdain for the mobility limitations that casts cause, especially since most residents perform various levels of manual labor for their occupation.

Further important findings were found when comparing patients who solely utilized bonesetters with patients who visited a doctor or nurse for cast immobilization. Interestingly, the bonesetter group had lower rates of continued pain, lower rates of limited movement, a higher satisfaction with their treatment, and a higher interest in seeking the same treatment in the future. It is important to note that none of these findings were statistically significant. Although these findings may be surprising to some, other studies have discovered benefits to bonesetting, as previously stated. It is also important to consider several factors when interpreting these results. First, a major limitation to this study is that these were all patient-reported bone fractures. Only $22 \%$ of participants had undergone radiography in the past to confirm a fracture. Therefore, a significant number of these "fractures" may have instead been sprains, strains, bruises, or other soft tissue injuries. If so, patients would likely improve overtime regardless of medical intervention and inaccurately report satisfaction and attribute success to their bonesetter, doctor, or nurse. Second, much of the patients' satisfaction may be due to the free/low cost of care, the ease of access to a bonesetter, their general likeness of their bonesetter, or other attributable factors. These are certainly important factors to support the use of bonesetters, but they do not necessarily support that the actual management of the fracture was adequate or backed my medical evidence. Third, none of these participants underwent physical evaluation during our interviews to assess mobility, range of motion, or pain, so participants may report better findings than what their medical evaluation would actually demonstrate.

Further research should use additional measurements, like physical examination and radiographs to assess outcomes. Moreover, additional local bonesetters should be engaged to further understand their approach to bone fracture treatment. Given the high use of bonesetters, further research could focus on how this cultural preference remains prevalent and how biomedical medicine can co-exist with bonesetters to improve patient care.

\subsection{Limitations}

Several of the major limitations have been touched on previously. These include the lack of radiographic evidence to support these patient-reported fractures, the potential mislabeling of fractures that were indeed a different musculoskeletal injury, and the inability to conduct physical examinations on patients to more objectively assess outcomes like function and pain levels. Another limitation is the innate constraint of using patient-reported data. Many of these fractures were many years ago, so we had to rely on human memory of the distant past. An additional limitation is the disproportionate number of female respondents. All interviews were conducted in the morning, which resulted in a disproportionate amount of female respondents because many men were outside of the household at work. Lastly, this study was conducted over a two-week span. It was supposed to be conducted over a three-week span, but was cut short due to the COVID-19 pandemic. This limited the number of interviews we were able to conduct.

\section{Conclusion}

Even with these considerations in mind, the perceived benefit and overwhelming preference for bonesetters in these communities cannot be denied. Moving forward, we would recommend that doctors and nurses in the region strive to cooperate and communicate with bonesetters in order to appropriately manage patients in need. Additionally, we would recommend that the use of X-ray be made more accessible and less costly in order to encourage patients to seek proper diagnosis of a fracture.

\section{Acknowledgements}

Thank you to the staff of Mayan Medical Aid in Santa Cruz La Laguna, Guatemala for their support of this project. Thank you to the interpreter who facilitated these participant interviews. Thank you to Dr. Mark Trottier, $\mathrm{PhD}$ and Michigan State University College of Human Medicine for their support throughout the development and completion of this project. 


\section{Competing Interests Statement}

The authors declare that there are no competing or potential conflicts of interest.

\section{References}

Anderson, R. (1987). The treatment of musculoskeletal disorders by a Mexican bonesetter (SOBADOR). Social Science \& Medicine, 24(1), 43-46. https://doi.org/10.1016/0277-9536(87)90137-7

Arcury, T. A., Sandberg, J. C., Mora, D. C., Talton, J. W., \& Quandt, S. A. (2016). North Carolina Latino Farmworkers' Use of Traditional Healers: A Pilot Study. Journal of Agromedicine, 21(3), 253-258. https://doi.org/10.1080/1059924X.2016.1180272

Ariës, M. J. H., Joosten, H., Wegdam, H. H. J., \& Geest, S. V. D. (2007). Fracture treatment by bonesetters in central Ghana: Patients explain their choices and experiences. Tropical Medicine \& International Health, 12(4), 564-574. https://doi.org/10.1111/j.1365-3156.2007.01822.x

Bickler, S. W., \& Sanno-Duanda, B. (2000). Bone setter's gangrene. Journal of Pediatric Surgery, 35(10), 1431-1433. https://doi.org/10.1053/jpsu.2000.16406

Caracterización de República de Guatemala. Instituto Nacional de Estadística Guatemala. (2014). Retrieved September 21, 2020, from http://www.ine.gob.gt/sistema/uploads/2014/02/26/L5pNHMXzxy5FFWmk9NHCrK9x7E5Qqvvy.pdf

Chen, Z.-J., Pan, X.-Y., Ma, Z.-H., Wu, J., Qi, Y.-Z., Ma, Y.-F., \& Li, X.-Y. (2018). [Lapidus operation combined with bone setting manipulation in treatment of hallux valgus in elderly patients]. Zhongguo Gu Shang = China Journal of Orthopaedics and Traumatology, 31(12), 1124-1128. https://doi.org/10.3969/j.issn.1003-0034.2018.12.010

Dada, A., Yinusa, W., \& Giwa, S. (2011). Review of the practice of traditional bone setting in Nigeria. African Health Sciences, 11(2), 262-265.

England, W. (1844). Lincolnshire and Cambridgeshire Bone-Setters. Provincial Medical and Surgical Journal, $8(33), 513$.

Estadística, I. N. de. (n.d.). Proyecciones. Retrieved September 21, 2020, from https://www.ine.gob.gt/ine/proyecciones/

GHO $\mid$ By category | Population —Data by country (all years). (n.d.). WHO; World Health Organization. Retrieved September 21, 2020, from https://apps.who.int/gho/data/view.main.POP2040ALL?lang=en

Hatipoğlu, S., \& Tatar, K. (1995). The strengths and weaknesses of Turkish bone-setters. World Health Forum, 16(2), 203-205.

Hemmilä, H. M., Keinänen-Kiukaanniemi, S. M., Levoska, S., \& Puska, P. (1997). Does folk medicine work? A randomized clinical trial on patients with prolonged back pain. Archives of Physical Medicine and Rehabilitation, 78(6), 571-577. https://doi.org/10.1016/S0003-9993(97)90420-2

Hemmilä, H. M., Keinänen-Kiukaanniemi, S. M., Levoska, S., \& Puska, P. (2002). Long-term effectiveness of bone-setting, light exercise therapy, and physiotherapy for prolonged back pain: A randomized controlled trial. Journal of Manipulative and Physiological Therapeutics, 25(2), 99-104. https://doi.org/10.1067/mmt.2002.122329

Hinojosa, S. Z. (2004). Bonesetting and Radiography in the Southern Maya Highlands. Medical Anthropology, 23(4), 263-293. https://doi.org/10.1080/01459740490506934

Hoff, W. (1997). Traditional health practitioners as primary health care workers. Tropical Doctor, 27(Suppl 1), 52-55. https://doi.org/10.1177/00494755970270S116

Huber, B. R., \& Anderson, R. (1996). Bonesetters and curers in a Mexican community: Conceptual models, status, and gender. Medical Anthropology, 17(1), 23-38. https://doi.org/10.1080/01459740.1996.9966126

James, S. L., Abate, D., Abate, K. H., Abay, S. M., Abbafati, C., Abbasi, N., .. Murray, C. J. L. (2018). Global, regional, and national incidence, prevalence, and years lived with disability for 354 diseases and injuries for 195 countries and territories, 1990-2017: A systematic analysis for the Global Burden of Disease Study 2017. The Lancet, 392(10159), 1789-1858. https://doi.org/10.1016/S0140-6736(18)32279-7

Kyu, H. H., Abate, D., Abate, K. H., Abay, S. M., Abbafati, C., Abbasi, N., ... Murray, C. J. L. (2018). Global, regional, and national disability-adjusted life-years (DALYs) for 359 diseases and injuries and healthy life 
expectancy (HALE) for 195 countries and territories, 1990-2017: A systematic analysis for the Global Burden of Disease Study 2017. The Lancet, 392(10159), 1859-1922. https://doi.org/10.1016/S0140-6736(18)32335-3

Montenegro, R. A., \& Stephens, C. (2006). Indigenous health in Latin America and the Caribbean. The Lancet, 367(9525), 1859-1869. https://doi.org/10.1016/S0140-6736(06)68808-9

“Municipio de Santa Cruz La Laguna Departamento de Sololá,, 2008” (PDF). Facultad de Ciencias Económicas Universidad de San Carlos de Guatemala..pdf. (n.d.).

Odatuwa-Omagbemi, D. O., Adiki, T. O., Elachi, C. I., \& Bafor, A. (2018). Complications of traditional bone setters (TBS) treatment of musculoskeletal injuries: Experience in a private setting in Warri, South-South Nigeria. Pan African Medical Journal, 30. https://doi.org/10.11604/pamj.2018.30.189.15730

Onuminya, J. E., Onabowale, B. O., Obekpa, P. O., \& Ihezue, C. H. (1999). Traditional bone setter's gangrene. International Orthopaedics, 23(2), 111-112. https://doi.org/10.1007/s002640050320

Portal de Resultados del Censo 2018. (2018). Retrieved September 21, 2020, from https://www.censopoblacion.gt/graficas

Roth, G. A., Abate, D., Abate, K. H., Abay, S. M., Abbafati, C., Abbasi, N., ... Murray, C. J. L. (2018). Global, regional, and national age-sex-specific mortality for 282 causes of death in 195 countries and territories, 1980-2017: A systematic analysis for the Global Burden of Disease Study 2017. The Lancet, 392(10159), 1736-1788. https://doi.org/10.1016/S0140-6736(18)32203-7

Smith, A. J. (1974). Medicine in China: Best of the old and the new. British Medical Journal, 2(5915), 367-370. https://doi.org/10.1136/bmj.2.5915.367

WHO $\mid$ Guatemala. (n.d.). WHO; World Health Organization. Retrieved September 21, 2020, from http://www.who.int/countries/gtm/en/

World Population Prospects—Population Division—United Nations. (n.d.). Retrieved September 21, 2020, from https://population.un.org/wpp/DataQuery/

Zehir, S. (2015). Bone-setter interventions and the Consequences. Acta Orthopaedica et Traumatologica Turcica. https://doi.org/10.3944/AOTT.2015.14.0358

\section{Copyrights}

Copyright for this article is retained by the author(s), with first publication rights granted to the journal.

This is an open-access article distributed under the terms and conditions of the Creative Commons Attribution license (http://creativecommons.org/licenses/by/4.0/). 